\title{
Intersticios intangibles: educación intercultural apoyada en las TIC, para el reconocimiento y visibilidad de la cultura makuna
}

INTANGIBLE INTERSTICES: ICT-SUPPORTED INTERCULTURAL EDUCATION FOR RECOGNITION AND VISIBILITY OF THE MAKUNA CULTURE

\section{INTERSTÍCIOS INTANGÍVEIS: EDUCAÇÃO INTERCULTURAL APOIDA NAS TIC PARA O RECONHECIMENTO E VISIVILIDADE DA CULTURA MAKUNA}

Widman Valbuena* / wsvalbuenab@unal.edu.co

Maximiliano García** / macuna.acaipi@gmail.com

Olga Vásquez $z^{* * * *} /$ olga.a.vasquez@gmail.com

Andrea Montoya $* *: * * /$

Juan Hernández ${ }^{* * * * *} /$ emailhernanedez@gmail.com

\section{Resumen}

En el presente documento se encuentran los hallazgos, las discusiones, los aportes y las proyecciones de la etapa inicial del estudio que se orienta hacia el desarrollo de un modelo educativo intercultural bilingüe macuna, apoyado en las Tecnologías de la Información y la Comunicación (TIC). Se considera que este modelo debe estar constituido, principalmente, por el conocimiento ancestral y ecológico del pueblo indígena macuna, por el conocimiento pragmático de la vida cotidiana de las personas de Caño Toaka que habitan la Selva Amazónica colombiana, por el conocimiento en técnicas ancestrales de aprendizaje y enseñanza (Århem, 2004) y por los aportes que desde la sociedad occidental, en términos de pedagogía y desarrollo tecnológico, se pueden hacer para cumplir con este propósito.

Los resultados se obtuvieron a partir de un proceso de investigación cualitativa, de alcance exploratorio y de carácter etnográfico para la recolección de información, cuyo tratamiento se basó en lo propuesto por la teoría fundamentada. Por medio de esto, se logra tener una descripción del estado actual de la educación intercultural en la comunidad en relación con el fenómeno técnico y la educación intercultural, la educación intercultural y las Tic y el objeto digital educativo intercultural; así mismo, se infieren las proyecciones para adelantar las etapas de diseño y desarrollo del modelo educativo intercultural apoyado en TIC, de modo que fortalezca la cultura macuna a través de: (1) procesos de apropiación de recursos culturales, (2) empoderamiento, (3) reconocimiento, y (4) visibilidad.
Palabras clave

Educación intercultural, TIC, visibilidad, cultura macuna, recursos culturales

\footnotetext{
1 Universidad de Caldas, Manizales, Colombia

2 ühü-Dueño de maloca, Caño Toaka, Vaupés, Colombia

3 University of California, San Diego, Department of Communication

4 Investigadora independiente, Bogotá, Colombia

5 International Corporation of Networks of Knowledge, ICONK, Bogotá, Colombia
}

Fecha de recepción: 14 de enero de 2016 / Fecha de aprobación: 24 de abril de 2016 


\section{Abstract}

This paper presents the findings, discussions, contributions, and projections of the initial stage of a study that is directed towards the development of a Macuna bilingual intercultural education model supported by information and communications technologies (ICT). The study suggests that this model should mainly be based on the ancient and ecological knowledge of the Macuna indigenous people, on the pragmatic knowledge of everyday life of the people of Caño Toaka, living in the Colombian Amazon rainforest, on knowledge of ancestral techniques of learning and teaching (Århem, 2004), as well as on the contributions of Western society in terms of education and technological development to the fulfillment of this purpose.

Results were obtained through a process of an exploratory qualitative research, of ethnographic character, for data collection; data analysis followed the proposal of grounded theory. Based on this, it was possible to describe the current state of intercultural education in the community in relation to technical phenomena and intercultural education, as well as intercultural education, ICTS, and the intercultural digital educational object; similarly, projections have been made to advance the different stages of design and development for the intercultural education model supported by ICTs, with the objective of strengthening Macuna culture through: (1) processes of appropriation of cultural resources, (2) empowerment, (3) recognition, and (4) visibility.

\section{Resumo}

No presente documento são apresentados os resultados, as discussões, os aportes e as projeções da etapa inicial do estudo que visa o desenvolvimento de um modelo educativo intercultural bilíngue macuna, apoiado nas Tecnologias da Informação e Comunicação (TIC). Considera-se que esse modelo deve estar constituído, principalmente, pelo conhecimento ancestral e ecológico do povo indígena macuna, pelo conhecimento pragmático da vida quotidiana das pessoas de Caño Toaka que moram na Selva Amazônica colombiana, pelo conhecimento em técnicas ancestrais de aprendizagem e ensino (Århem, 2004) e pelos aportes que desde a sociedade ocidental, em termos de pedagogia e desenvolvimento tecnológico, sejam adequados para esse propósito.

Os resultados foram obtidos a partir de um processo de investigação qualitativa de alcance exploratório e de caráter etnográfico para a recolecção de informação, cujo tratamento se baseou na proposta da teoria fundamentada. Por médio disso, logrou-se obter uma descrição do estado atual da educação intercultural na comunidade em relação com o fenômeno técnico e a educação intercultural, a educação intercultural e as TIC e o objeto digital educativo intercultural; assim mesmo, foram inferidas a projeções para adiantar as etapas de planejamento e desenvolvimento do modelo educativo intercultural, apoiado em TIC, para fortalecer a cultura macuna através de: (1) processos de apropriação de recursos naturais, (2) empoderamento (3) reconhecimento, e (4) visibilidade.

\section{YERO A BTSIRE}

Adi ya oka ado bahiro $\sim$ riakare riasoha $\sim$ kedaroha gawaye $\sim$ raka hoari $\sim$ gada-ye $\sim$ rakaktdy yikoari makuna $\sim$ ida btsigore. Gta $\sim$ boare ktti $\sim$ yaro bahiroti gta $\sim$ ria $\sim$ basi-ware $\sim$ aboa yiwara $\sim$ ida $\sim$ abosarise $\sim$ ya adi. Ado bahiro tto $\sim$ iakoari gawayere $\sim$ ktdi $\sim$ kedaro gta $\sim$ ria $\sim$ ida riasotire $\sim$ aboa gta $\sim$ basa yirise oka $\sim$ ya adi.

$\sim$ Basa raka btsi $\sim$ koari, btkt $\sim$ rare tto $\sim$ koari ado bahiati ya adi oka. Ado bahiro $\sim$ boare kttiha $\sim$ kedaroha toaka $\sim$ gada $\sim$ raka yi ttoiakuado bahiroti oka $\sim$ ya ado. Iti ti $\sim$ koari ado bahiro bahi $\sim$ yati $\sim$ riaka ida papera tiirisre, ito bahiro iti bahiha ba ado bahirojta boa ha kenarohati yirise ya adi oka. Ado bahiro $\sim$ idare riasoha kedaroha gawa ya gaho $\sim$ di kedoro $\sim$ ida rtko $\sim$ basitodi yirise $\sim$ ya adi oka. Ito yi $\sim$ koari basa heyaro $\sim$ ida tiroti $\sim$ ya-toha adi oka yi ttoia $\sim$ koari $\sim$ basa $\sim$ ida $\sim$ amorise $\sim$ ya adi.

\section{Keywords}

Intercultural education, ICT, visibility, Macuna culture, cultural resources.

\section{Palavras chave}

Educação intercultural, TIC, visibilidade, cultura macuna, recursos naturais

1 El equipo de investigación, en coherencia con los resultados y la prospectiva que aquí se plantean, ha decidido que, como un ejemplo de la validación y visibilización de las lenguas indígenas, este artículo debe presentar, por lo menos, el resumen en lengua makuna o ide masã. 


\section{Introducción}

A lo largo de las últimas tres o cuatro décadas, en diversas partes del mundo las naciones han estado experimentando con una educación bilingüe intercultural que tenga en cuenta los recursos culturales y lingüísticos de los pueblos indígenas. A pesar de estos esfuerzos y del reconocimiento de la situación de varias poblaciones indígenas, el currículo y la instrucción de estos nuevos programas sigue centrada en la asimilación (Baker, 2001; Heath, 1993).

El equipo de investigación transnacional y transcultural ha sido invitado por el Ühü o dueño de maloca (líder tribal), de la comunidad makuna de Caño Toaka, ubicada en la esquina sureste de la Amazonía colombiana, quien ve no solo la necesidad de agregar un modelo de educación que incorpore el conocimiento ancestral y ecológico, sino también, la necesidad de recopilar, gestionar y distribuir el conocimiento ancestral y ecológico de la comunidad, que se ha estado recogiendo durante una década.

Como se puede ver más adelante, la educación en la zona ha pasado por importantes transformaciones (figura 2) que han impactado la vida cotidiana, al traer consigo problemas ecológicos, sociales y culturales. En la actualidad, se manifiesta la necesidad de reorientar los procesos educativos de modo que se atenúen estos impactos teniendo muy presente, primero, las actuales relaciones que los indígenas han establecido con la sociedad mayoritaria, y, segundo, las actuales condiciones socioculturales de las sociedades occidentales u occidentalizadas, donde, por ejemplo, es innegable cómo las TIC han permeado la cotidianidad de las personas y las instituciones y constituido una sociedad de relaciones intermitentes, efímeras y de estructuras disipativas (Bauman, 2000, 2007).

Este documento se centra en el papel que juegan las TIC en la mejora de la capacidad de un innovador Proyecto Educativo Comunitario (PEC) para contrarrestar la hegemonía simbólica y material de la Iglesia católica y el Estado colombiano, y proporcionar un lugar para el empoderamiento comunitario y la visibilidad. Específicamente, se centra en los efectos de la infraestructura de soporte digital en la autodeterminación del pueblo Ide Masã (Gente del Agua) para definir el contenido y los objetivos de una educación que se inserta en su proyección social y su cosmovisión. Se trata de desentrañar los efectos particulares que la visibilidad de las prácticas locales y el conocimiento ancestral y ecológico tienen en el fortalecimiento de la cultura nativa; todo ello, contando con la colaboración entre los líderes tribales e investigadores colombianos y extranjeros, y procurando el diseño de un modelo de educación que satisfaga las metas y los objetivos de la sociedad makuna.

Los objetivos de este trabajo van más allá de la descripción del proceso de instalación de una infraestructura digital para apoyar una cruzada nacional y la colaboración intercultural bilingüe en el desarrollo de un modelo de educación intercultural indígena; lo que se busca es hacer el seguimiento a los efectos de la visibilidad en las prácticas locales y en el empoderamiento de la comunidad. Se considera que el concepto de las TIC no se limita al uso del computador, pero se lo concibe como un enfoque sociocultural complejo de la Ciencia-Tecnología-Sociedad (CTS) o como un socioecosistema tecnológico (Osorio, 2002), en el que los procesos de poder y el uso de los recursos para fines específicos dan lugar a cambios constantes que se pueden entender como innovación. Lugo y Kelly (2010) sugieren que la innovación no se limita a suponer la incorporación de recursos tecnológicos, sino que significa una transformación cultural en la manera de gestionar y desarrollar el conocimiento, las estrategias de enseñanza, los ajustes institucionales nuevos, los roles de los actores, e, incluso, la manera creativa de pensar la educación y la tecnología.

El problema de investigación que orienta el presente estudio se instala en cómo desarrollar un modelo de educación intercultural multilingüe makuna apoyado en TIC, de modo que este fortalezca la cultura makuna desde una metodología participativa basada en la construcción colectiva y el diálogo de saberes.

Para lo anterior, se ha planteado un análisis de la situación actual de la educación en la comunidad de Caño Toaka en relación con las TIC, desde tres categorías principales: fenómeno técnico y educación intercultural; educación intercultural y TIC, y Objeto Digital Educativo Intercultural (ODEI). 


\section{Fenómeno técnico y educación intercultural}

Desde una perspectiva que supera la visión artefactual de la tecnología como la más común (Osorio, 2002), se entiende aquí que las sociedades, como parte de su propio desarrollo, establecen relaciones con su entorno natural, que "comprende al conjunto de características históricamente determinadas, por las cuales captamos la técnica de una determinada época" (Osorio, 2002, párr. 42 ); este conjunto de relaciones que caracterizan una época es lo que Carlos Osorio denomina fenómeno técnico.

Para el presente estudio, este fenómeno técnico comprende características no solo históricamente determinadas, sino geográficamente constituidas; no desde una perspectiva reduccionista-racionalista de la geografía, sino desde la construcción social del espacio teniendo en cuenta los componentes físicos y simbólicos que las personas generan en relación con su entorno vital transformando espacios en lugares, y estos, en un sistema complejo que configura el territorio como se entiende desde la geografía humanística, es

mediante conceptos y símbolos que el hombre convierte el espacio en algo ligado a él por estrechos lazos emotivos, y ello ocurre incluso en marcos amplios de los que no dispone de experiencias directas. En estos casos, estos espacios que superan la experiencia directa de la gente pueden llegar a transformarse en focos de «lealtad apasionada» a través de símbolos o mediante la educación y la política (Tuan, 1976, p. 268). (Estébanez, 1982, p. 16).

La geografía humanística de la gente del agua está constituida por el conjunto de experiencias sensoriales e imaginarias que explican y regulan la vida cotidiana, como ejemplo, los mundos paralelos que los sabedores $\left(\right.$ Paye $\left.^{2}\right)$ habitan en el momento de las curaciones (Århem et al., 2004).

Es así como el fenómeno técnico comprende rasgos temporales, físicos y simbólicos que (para el caso, en la comunidad indígena de Caño Toaka) lo determinan e

2 Nombre cotidiano que reciben los especialistas culturales dedicados a realizar las curaciones en los rituales. Estos especialistas también se denominan chamanes en la literatura antropológica y en lengua propia estos expertos culturales son conocidos y reconocidos como Kũmu/he gu (Cayón, 2013). involucran la caracterización de los lugares, entendidos estos como el espacio significado, el cual, desde la postura de la geografía de la vida cotidiana, adquiere sentido de lugar e implica reconocer los lugares no solo como una realidad material, sino como una construcción sociocultural que emerge desde las prácticas cotidianas, $y$, por ende, se impregnan de sentidos y significados (Montoya, 2012). En ese sentido, cuando se entra en contacto con intangibles (sentidos y significados) ajenos a los lugares tradicionalmente construidos, estos se transforman, porque a pesar de mantener en su mayoría el componente físico (como, por ejemplo, el río), este cambia de significado, es otro lugar y la relación técnica con este pasa por metamorfosis simbólica; por supuesto, ello supone un impacto en la cultura y en su relación con la educación como vehículo social de reproducción y transformación cultural.

En términos de las TIC, habría aquí que ampliar el horizonte de comprensión meramente técnico-occidental, y entender que, por ejemplo, las lenguas nativas y la tradición oral son el desarrollo más sofisticado del fenómeno técnico comunicacional entre las personas de las comunidades amazónicas; pero, igualmente, los rituales de curación o de negociación con los seres dueños del territorio (Ayawa), así como sus componentes físicos de intercambio (el tabaco y la coca) y los significados culturales asociados a estos, son, sin duda, tecnologías que permiten la comunicación y el intercambio de información.

Esta perspectiva, desde luego, supera la simplista consideración de las TIC como artefactos técnicos de desarrollo occidental y de carácter únicamente digital. Como se podrá ver más adelante, se intentó reemplazar mucho de este desarrollo cultural a través de la educación por otras tecnologías exógenas, como la escritura y el castellano; empero, la tecnología del lenguaje oral ha prevalecido, a pesar de la transformación de su contenido simbólico, y se constituye actualmente en una de las principales herramientas para el fortalecimiento cultural.

\section{Educación intercultural y TIC}

La educación intercultural se entiende como un proceso educativo basado en la interacción entre personas de grupos culturalmente diferentes (Schmelkes, 2004), 
y puede ser apoyada por las TIC. En tal sentido, esta se aborda con una perspectiva que articula procesos educativos con el contexto sociocultural (Ferrão, 2010) y que considera acciones pedagógicas reconociendo impactos culturales económicos, políticos, ecológicos y sociales del contexto. De acuerdo con ello, es necesario que el proceso educativo se desarrolle mediante un diálogo de saberes; o, en términos de Tubino (2005), un diálogo dado como un proceso de interculturalidad crítica, lo cual implica la superación de la asimetría social que pueda existir entre las culturas involucradas. La importancia de un diálogo simétrico reside en que, al tiempo que se reconocen diferencias, se promueve el respeto, lo que deriva en espacios propicios para la apropiación de recursos culturales exógenos, en vez de la imposición de estos.

Así mismo, este proceso de apropiación implica un proceso de transformación, en el que es fundamental asumir un compromiso de reconocimiento del contexto con todos los elementos que lo componen; es decir, los elementos sociales, culturales y ecológicos a través de los cuales se configura el habitar de la comunidad (Valbuena, 2006). En ese sentido, pensar en las TIC como un elemento a través del cual se aporta a la configuración del contexto permite reconocer lo que Ortiz y Aguilar (2010) plantean como el trinomio perfecto, conformado por la lengua, la cultura y las TIC, reconocido en un contexto intercultural, tomando en cuenta que

la interculturalidad tiene que ver con el intercambio de costumbres, tradiciones, ideas, valores y conceptos que van más allá de la simple adquisición de información referente al otro, sino que incluye el saber cómo te perciben los otros y el intercambio de conocimientos y actitudes. (Byram y Zarate, en Ortiz y Aguilar, 2010, p. 480).

No obstante, en relación con el conocimiento desde el contexto de la comunidad de Caño Toaka, se considera que este no se concibe como un intercambio, sino como un producto que emerge de la interacción y de la construcción conjunta; es decir, la educación intercultural implica comprender las culturas involucradas, lo cual deriva de la interpretación de estas a través de los criterios culturales propios. Según eso, es importante, como lo plantean Ortiz y Aguilar (2010), moderar un inevitable etnocentrismo que lleva a interpretar las prácticas culturales ajenas a partir de los criterios de la cultura de quien interpreta. Por tanto, se trata de reconocer los recursos propios y los ajenos (Bonfil, 1995), y así dar cabida a que se generen procesos de apropiación de estos en doble vía, pues el encuentro entre culturas suscita el aprendizaje del otro y con el otro.

En ese propósito, desde la educación intercultural es importante configurar Tıc digitales interculturales; como tales se consideran las que permiten generar un puente a través del cual es posible establecer la acción comunicativa desde la interacción mediada por símbolos (Habermas y Redondo, 2001). Al respecto, Ortiz y Aguilar (2010) plantean que las TIC permiten configurar entornos virtuales afrontando las restricciones del tiempo y permitiendo el acceso a la comunicación, y, por ende, aportando a la cooperación y la construcción conjunta de conocimientos híbridos (García, 2004). Es importante que esta configuración emerja desde la cotidianidad de la comunidad, la cual se constituye en un lugar estratégico para pensar la sociedad en su compleja pluralidad de símbolos y de interacciones, ya que se trata del espacio donde se encuentran las prácticas y las estructuras, del escenario de la reproducción y, simultáneamente, de la innovación social (Reguillo, 2000).

Al respecto, Sosa, Peligros y Díaz (2010) destacan que la simple instalación de los equipos informáticos o el uso de estos medios de comunicación con una metodología tradicional no es una buena práctica tan solo porque se insiste en la importancia de pensar en el uso apropiado de la tecnología en contextos con situaciones muy específicas. En el caso de las comunidades indígenas, es particularmente importante situar esta cuestión en la presente investigación; ello, teniendo en cuenta el estado actual de invisibilidad externa de los procesos educativos en la comunidad indígena de Caño Toaka.

Adicionalmente, estos autores ofrecen las mejores prácticas educativas a través de las TIC, en las que estas tienen el potencial de mejorar el proceso de enseñanzaaprendizaje que podría muy bien resultar en el capital económico, social y cultural. Por su parte, Lugo y Kelly (2010) proponen que la integración de las prácticas de las TIC en América Latina debe ser entendida como una oportunidad para generar innovación educativa. 
A partir de este sentido, es importante reconocer que simplemente incorporar artefactos digitales no es pertinente a las necesidades de la sociedad, pues el enfoque está en promover iniciativas que favorezcan la utilización de esa tecnología incorporada. Del mismo modo, los autores proponen que la atención debería centrarse en la transformación cultural de la manera de gestionar y construir el conocimiento, lo que afecta las estrategias de los procesos de aprendizaje, y reconociendo que el proceso de cambio es en respuesta a una necesidad. Estas posibilidades son consecuentes con los lineamientos y los objetivos del plan de vida de muchas comunidades indígenas de la región.

Por lo anterior, vemos cómo las TIC tienen una doble función que va más allá de la aproximación de la herramienta (Osorio, 2002). Por un lado, se localiza un conjunto complejo de conocimientos, necesarios para su reinvención y su adaptación al modelo intercultural bilingüe educativo que nos ocupa. En esencia, las TIC pueden proporcionar el "tercer espacio" (Gutiérrez, 2008) para establecer un laboratorio cultural para la innovación del desarrollo sociocultural con un enfoque pedagógico.

La colaboración con los líderes tribales para desarrollar un modelo de educación bilingüe intercultural basado en las herramientas ecológicas y culturales de la comunidad hace que sea imperativo ampliar nuestra base teórica desde la ecología cultural y la geografía humanística (Cayón, 2008, 2013; Descola y Palsson, 2013; Montoya, 2012; Valbuena, 2006), el multiculturalismo (Rappaport, 2005), la educación intercultural bilingüe/ multilingüe (López y Sichra, 2008; Moya, 1999) y la lengua indígena y la educación (Hornberger, 1998; McCarty, 2003; Schmelkes, 2004). Estas nuevas perspectivas no solo nos ayudan a identificar y adaptar los recursos de la comunidad para la educación; además, se convierte en obligatorio para el equipo de investigación examinar las implicaciones políticas de nuestro contenido y la entrega de nuestros procesos educativos. Por lo tanto, estas teorías nos ayudarán a evitar los escollos que, con pocas excepciones, enfrentan los otros proyectos de educación intercultural (Rappaport, 2005), tales como el aumento de la marginación, la exclusión y la asimilación de los pueblos indígenas en toda América Latina (Baker, 2001; Heath, 1993; López y Sichra, 2008).

\section{Objeto digital educativo intercultural (ODEI)}

En el presente estudio, se entiende el objeto digital educativo intercultural (ODEI) como el objeto que habilita la acción comunicativa (Habermas y Redondo, 2001) entre dos o más culturas; se caracteriza, además, por la configuración de nuevas arquitecturas del lenguaje desde los fundamentos de la digitalidad (Martín-Barbero, 2008) y se lo entiende como un gestor de las transformaciones de los significados existentes en nuevos significados interculturales.

En ese sentido, para que en realidad exista un ODEI Se debe dar por superado lo que Castells (2000) presenta como "divisoria digital", lo cual consiste en que no todas las culturas que están entrando en comunicación disponen de acceso al mundo digital; por ello, si no se garantiza la acción comunicativa entre todas las culturas que se están vinculando a través de entornos digitales, se puede pensar que el objeto digital no es completamente intercultural, que no se trata, en realidad, de un artefacto que sirva de ambiente para la innovación cultural.

Es así que las tres acciones propuestas por Boast, Bravo y Srinivasan (2007) se hacen relevantes en términos de: primero, crear una metodología propia de la gestión de conocimiento basada en el uso de TIC, que sea acorde a las necesidades de las diferentes culturas que configuran el complejo intercultural; segundo, hacer útil el conocimiento disponible, y tercero, que el ODEI debe permitir que los usuarios sean los gestores del conocimiento, $y$ que como producto de dicha gestión se genere nuevo conocimiento en el contexto intercultural.

Uno de los aspectos considerados dentro de la categoría de ODEI es la visibilidad; Hernández y Valbuena (2010) proponen que la visibilidad en un contexto de aprendizaje tiene tres atributos principales, que influyen significativamente en la forma como se construye el fortalecimiento de la colaboración y el conocimiento: (1) atributos de identidad (los atributos individuales y colectivos); (2) atributos de interacción y (3) atributos de registro. En ese sentido, se considera útil relacionar el estudio de la visibilidad con el desarrollo psicológico y cognitivo de las personas, y, específicamente, 
desde el concepto de zona de desarrollo próximo (ZDP), establecido por Vygotsky (1978), ya que este activa la conciencia de la acción del individuo como individuo y su relación con los otros, y así fortalece la resolución de problemas de manera colectiva.

Como complemento, Brighenti (2010) elabora el concepto de visibilidad como una categoría general para la teoría social. Este autor define la visibilidad en disciplinas y campos como la sociología, los estudios culturales, los medios de comunicación, las ciencias políticas, los estudios urbanos, los estudios de identidad y la tecnología. Para la presente investigación, tiene mayor interés el enfoque que se le da desde la sociología, los estudios de la cultura y los estudios científicos y tecnológicos, pues la visibilidad se ha venido entendiendo como un factor clave para activar la gestión del aprendizaje de los individuos y los colectivos.

Así mismo, Scribano (2004) desarrolla el concepto de visibilidad en relación con el reconocimiento, el prestigio, la evaluación, el intercambio y la valoración, y en tal sentido se propone en este proyecto el ODEI Como un producto contextual que debe ser relevante para un grupo social, con unas características definidas que garanticen su utilidad; en esos términos, se encuentra una nueva orientación de desarrollo de la investigación.

Los retos a los que se enfrenta el equipo de investigadores están orientados a pensar en el desarrollo de un ODEI COmo un elemento potenciador de la visibilidad de los recursos culturales y epistemológicos de un conjunto de culturas. Desde este enfoque, se reconocen las potencialidades de los medios digitales en términos de la posibilidad en los canales de interacción.

\section{Materiales y método}

Teniendo en cuenta que el objetivo del presente proyecto se orientó a establecer el estado actual de la relación entre la educación intercultural y las TIC en la comunidad indígena de Caño Toaka, se planteó ubicar el estudio dentro del paradigma cualitativo en un enfoque epistemológico de orden hermenéutico-interpretativo con carácter etnográfico, y como tipología, la investigación aplicada con alcance exploratorio-descriptivo.
Las técnicas y los instrumentos utilizados para recolectar la información fueron la observación participante con registro en diario de campo, la entrevista en profundidad y el conversatorio con guía de discusión semiestructurada.

\section{Diseño metodológico}

Se tomó como población de estudio a las comunidades indígenas del Pirá Paraná, en el Departamento de Vaupés, Colombia. La unidad de análisis corresponde a la comunidad de Caño Toaka, conformada por 87 personas entre hombres, mujeres, niños y niñas. De acuerdo con ello, se aborda como enfoque metodológico la etnografía, a partir del cual se establece la ruta metodológica, que contempla cinco etapas, como se presenta en la figura 1.

Figura 1. Ruta metodológica de la investigación.

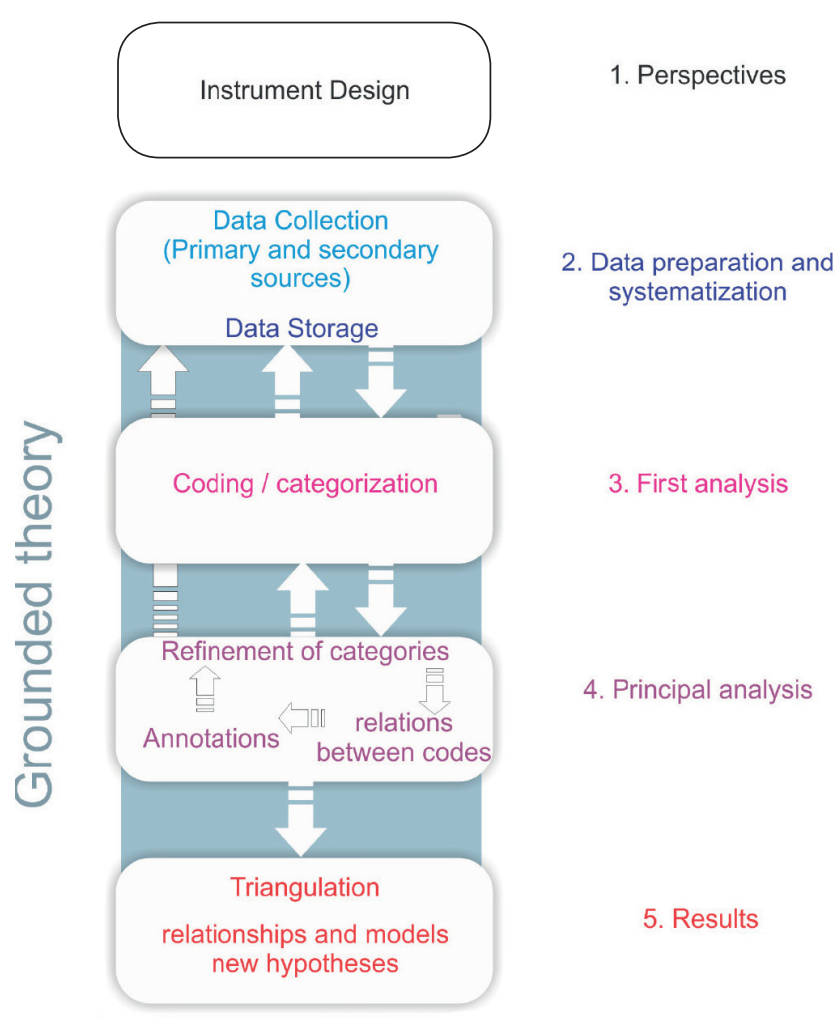

Adecuación de W. Valbuena (marzo de 2013).

\section{Perspectivas}

El proyecto se aborda desde cuatro posturas que permiten asumir una mirada holográmica del objeto de 
estudio (Morin, 1999; 2004): las TIC en relación con la educación intercultural; las prácticas educativas locales; el conocimiento ecológico y cultural, para dar cuenta de la construcción social del espacio desde lo cotidiano, y la política y las relaciones de poder. De acuerdo con dichas perspectivas, se definieron como técnicas de investigación la observación participante, la entrevista en profundidad y el conversatorio; además, se diseñaron los instrumentos para el registro en campo, el diario de campo, la entrevista y la guía de conversación semiestructurada.

\section{Preparación de datos y sistematización}

Esta etapa involucra la recolección de información desde fuentes primarias, a través del trabajo de campo, en el cual se lleva a cabo el registro de información abordando las cuatro perspectivas que orientaron la búsqueda: TIC en relación con la educación intercultural, prácticas educativas locales, política y relaciones de poder, y conocimiento ecológico y cultural. Para ello, se hace observación participante en la comunidad desde las dinámicas cotidianas y entrevistas en profundidad a diferentes actores, y se establecen conversatorios con líderes tribales y con los hombres y las mujeres de la comunidad. Por otro lado, se recolecta información desde fuentes secundarias a través de la revisión de literatura tomando como eje el problema de investigación, que se orienta a responder cuál es el estado actual de la educación local en relación con las TIC en la comunidad indígena de Caño Toaka.

\section{Análisis inicial}

Para el análisis inicial se estableció la definición conceptual de las categorías que orientan tanto la recolección como el procesamiento de la información; estas son: fenómeno técnico y educación intercultural; educación intercultural y TIC, y ODEI.

\section{Análisis principal}

A partir de lo anterior, se realiza un proceso de refinamiento categorial a través de la relación entre las mismas categorías y la reflexividad (Guber, 2001) de los investigadores desde la relación entre la teoría formal y la teoría sustancial (Montoya, 2012).

\section{Resultados}

A través de la triangulación entre fuentes primarias y secundarias, se establecen los modelos explicativos y las relaciones en redes semánticas para plantear los resultados del estudio materializados en conclusiones, supuestos y proyecciones.

\section{Resultados y discusión}

\section{El fenómeno técnico en la educación intercultural}

En el proceso participativo para la construcción de una educación intercultural asistida por TIC, es fundamental tener presente las actuales características técnicas de la comunidad de Caño Toaka. En principio, es importante reconocer, describir y entender todo el desarrollo técnico que el pueblo Makuna ha construido como parte de su cultura estableciendo relaciones con la selva, con el fin de proteger la vida saludable. Este reconocimiento no debe quedarse en un inventario de producción material, sino trascender hacia el sentido simbólico de esta producción; es decir, establecer las conexiones entre lo material y lo simbólico.

Así mismo, es importante reconocer la influencia material y simbólica de los desarrollos técnicos exógenos, ya que, como se puede observar en el siguiente fragmento de un conversatorio con el líder tribal, existe un impacto sutil, pero profundo, de estos objetos en la actual vida cotidiana de las personas:

(...) entonces entran los europeos, los portugueses y los colombianos, entran mercancías, de fácil uso (...) como la olla, la escopeta, el anzuelo, el nylon, la hamaca. Entonces ahí se van rompiendo otras reglas de conocimiento, como hay ya hamaca hecha, entonces no hay ya necesidad de buscar materiales en la selva; como ya hay escopeta, como ya hay nylon, entonces no hay la necesidad de seguir utilizando las herramientas culturales convencionales de cacería (...) entonces eso se va quedando atrás; igualmente con las ollas, que es mucho más práctico una olla de aluminio que una olla de barro, en una olla de barro una carne de danta, por ejemplo, una carne de lapa, uno 
puede estar cocinando por ahí una hora, mientras que en la de aluminio en quince minutos ya está preparada la comida (...) (sic). (Conversación personal con líder tribal, 2012).

Es evidente el impacto del uso de artefactos tecnológicos ajenos sobre la vida cotidiana, donde estos han desplazado el tipo de conocimiento técnico local por valores técnicos externos como la eficiencia técnica. Esto, obviamente, se relaciona con la educación, ya que, como se ha podido establecer, la forma más común como el niño indígena aprende lo básico para vivir en la selva es a través del ejemplo de los mayores; si estos transfieren consciente o inconscientemente esos nuevos valores por medio del ejemplo diario, lo más probable es que dichos valores queden instalados subjetivamente en el niño. Esto, como se puede observar, ha impactado igualmente el acervo cultural del grupo étnico, que como consecuencia de la apropiación del artefacto ha olvidado técnicas tradicionales. Por supuesto, es importante reconocer que al mismo tiempo se han desarroIlado habilidades en el uso eficiente de esos artefactos; empero, el conocimiento sobre esta tecnología externa no supera lo instrumental, pues lo que llega a la comunidad es el artefacto terminado, mas no el conocimiento detrás de la producción y el uso de este.

Por otro lado, se debe tener presente que en la actualidad las condiciones técnicas y ambientales dificultan la comunicación con los miembros de la comunidad, como se observa en el siguiente comentario: "el contacto es un poco difícil, pero a través de personas se puede" (sic). (Conversación personal con líder tribal, 2012).

En este momento, las personas se convierten en el canal de comunicación con el exterior; para ello, estas se asisten de uno de esos artefactos externos que han sido instrumentalmente apropiados, y el cual constituye hoy el mejor recurso técnico para la comunicación con Caño Toaka desde el exterior; se está hablando de la radiofonía.

La radiofonía es utilizada por las personas que han tenido algún tipo de formación en el uso de estos artefactos, lo cual da entrada a otro componente de la problemática, relacionado con el hecho de que la mayoría de las personas que actualmente viven en Caño Toaka no han tenido acceso al uso de TIC de este tipo, lo cual sugiere idear un proceso para que puedan tener acceso a este tipo de tecnologías, de modo que se activen la interacción y el flujo de saberes en doble vía.

Como recurso cultural propio en términos de TIC, se debe contemplar aquí el desarrollo lingüístico como una de esas tecnologías que se han usado tradicionalmente para fortalecer la cultura makuna. Indudablemente, un modelo intercultural debe asirse de este importante recurso desde sus formas más tradicionales; en particular, la lengua hablada. La palabra es el artefacto cultural más importante en un modelo de educación intercultural multilingüe en la comunidad.

\section{Prácticas educativas locales, la educación es el problema}

Conversando con los líderes indígenas, ellos nos enseñan que "(...) para que la gente pueda vivir, se plantean reglas (...)". De las poblaciones indígenas del Pirá Paraná hemos aprendido que la educación es para la vida, y, por tanto, inferimos que para desarrollar un modelo intercultural debemos adentrarnos profundamente y entender la vida de las personas en la comunidad para recomponer la educación en su función básica.

Una fuente importante de conocimiento ancestral y material cognitivo, y, por ende, también de los procesos educativos locales, se instala en los sueños de las personas, los cuales son, según su propia cosmovisión, proporcionados por la maloca y su atmósfera.

La maloca es importante porque ella representa el cielo o el cosmos que nos da aire y viento para que podamos respirar aire puro, la maloca purifica el aire, nos da aire de conocimiento. Ella nos da los sueños que nos traen conocimiento, a través de los sueños aprendemos a interpretar significados de diferentes sucesos y eventos que transcurren a diario en nuestra vida. (Manuscrito García, 2011).

Infortunadamente para la cultura de las comunidades del Pirá Paraná, este tipo de consideraciones no se han tenido en cuenta, ya que los agentes externos han establecido relaciones asimétricas y desiguales con ellos.

Al preguntar qué cosas, entre los momentos de la vida de los indígenas, han hecho más daño a las culturas indígenas, se comenta que existen en la historia cultural 
de los pueblos del Pirá Paraná cinco momentos que impactaron negativamente el natural desarrollo cultural, en una suerte de aniquilación simbólica:

El primer momento, denotado como "cauchería3", donde el contacto con los europeos se recuerda por el exterminio físico de las personas (sobre todo, adultos) que vivían en las cercanías de los grandes ríos. Este primer contacto no tuvo un impacto significativo en los niños, debido a que estos no eran considerados una fuerza de trabajo productiva; empero, indudablemente, ser alejados de sus padres de forma violenta tuvo algún impacto en la formación del niño indígena.

En un segundo momento se ubica la evangelización por parte de la Iglesia, donde se comenta que esta no habría prosperado sin la educación como instrumento. Esta nueva intromisión causó un importante deterioro a las culturas indígenas, porque sistemáticamente está dirigida tanto a los adultos como a los niños, lo que ocasiona una ruptura generacional y simbólica que impacta la vida cotidiana, pues los niños son desplazados de su cotidianidad e instalados a la fuerza en otra que subvalora y niega su origen.

En un tercer lugar se encuentra la denominada "cacería"4. En este momento ingresan mercancías de fácil uso, y allí, en términos del Ühü-dueño de maloca, se van rompiendo reglas de conocimiento, porque los nuevos objetos reemplazan sus prácticas cotidianas (fenómeno técnico); es este un encuentro de dos lógicas de consumo diferente. Por un lado, las prácticas locales se ubican en la producción y el intercambio de productos (este intercambio es, incluso, simbólico con los seres creadores y dueños del territorio); por otro, se encuentra la lógica del comerciante, que se caracteriza por ser errática y estar en plena transformación de una sociedad occidental de productores a una sociedad de consumidores (Bauman, 2007). En este encuentro chocan diferentes significados y valores, donde la eficiencia técnica se impone por encima de la tradición, y, por su parte, los comerciantes, haciendo uso de la lógica

3 Se conoce como "cauchería" el momento histórico en el cual la extracción de la savia del árbol de caucho era común en la vida cotidiana de la Amazonía.

4 Como ejemplo de esta práctica se encuentra la cacería de pieles de tigrillo y de otros animales silvestres con fines comerciales. de intercambio propia de las comunidades indígenas, establecen relaciones comerciales aprovechando esto para intercambiar el trabajo de las personas por algunos artefactos, en una especie de "marketing artesanal".

Lo anterior, sin ser únicamente propio de los espacios escolares, tiene un impacto profundo en la educación de los niños y los jóvenes indígenas, quienes se enfrentan a la disyuntiva de acceder a una educación propia para preservar su cultura u optar por los nuevos valores intercambiando o "vendiendo" su fuerza de trabajo para obtener objetos que gracias, entre otras cosas, al proceso de evangelización han adquirido un aura de prestigio.

En este mismo momento, la escuela y la Iglesia, con la política de civilización, generan un impacto muy fuerte en la transformación cultural prohibiendo a los niños hablar su lengua nativa; es decir, la TIC originaria es desplazada a la fuerza por la TIC exógena.

El cuarto momento se presenta con el auge de la coca; ello, sin dejar de actuar la evangelización, a través de la educación escolarizada. Este auge hace que las personas jóvenes se desplacen a otros lugares por mucho tiempo; de nuevo, se impacta profundamente la cotidianidad, y, como consecuencia, el conocimiento ancestral que tienen los más viejos de la comunidad se queda con pocos receptores en las nuevas generaciones. Este momento, igualmente, se caracteriza por la amplificación de la escolarización, a cargo de la Iglesia, como método para instalar en los niños valores ajenos.

Finalmente, aparece la minería como una manifestación más de la aniquilación simbólica sembrada por la escolarización, y que, al mismo tiempo, la amplifica. Esta no es sino otra de las formas como intereses externos (generalmente, de orden economicista) aprovechan el trabajo hecho por la evangelización para sacar provecho de los recursos naturales de la zona contratando la fuerza de trabajo indígena a cambio de un falso prestigio. La única diferencia en cuanto a la intervención de la educación escolarizada en ese momento es que esta ya no está únicamente en manos de la Iglesia, sino que comparte dicha función con el Estado colombiano, el cual administra para este momento buena parte de la educación por medio de la vinculación de las escuelas al sistema educativo departamental. 


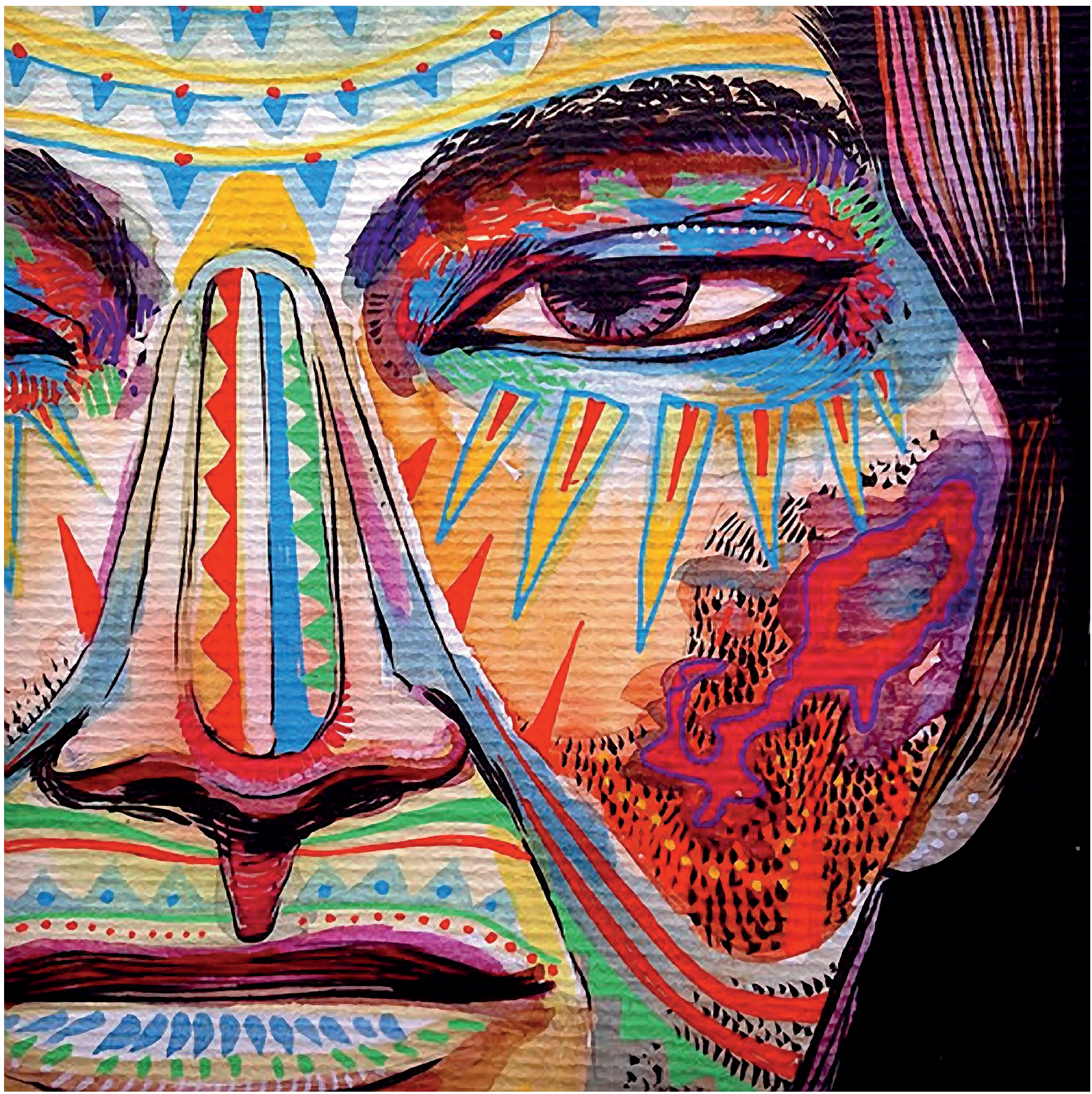


Todos los anteriores momentos amplifican el efecto de la evangelización, que, armada con la educación como dispositivo de aniquilación cultural, emprende una disputa simbólica, ya que es en ese momento cuando se siembra la semilla ideológica introduciendo valores ajenos que distorsionan y tuercen el desarrollo natural de la cultura, y así cambian drásticamente su patrón originario (figura 2).

Figura 2. Modelo de transformación cultural en el Pirá Paraná, Vaupés.

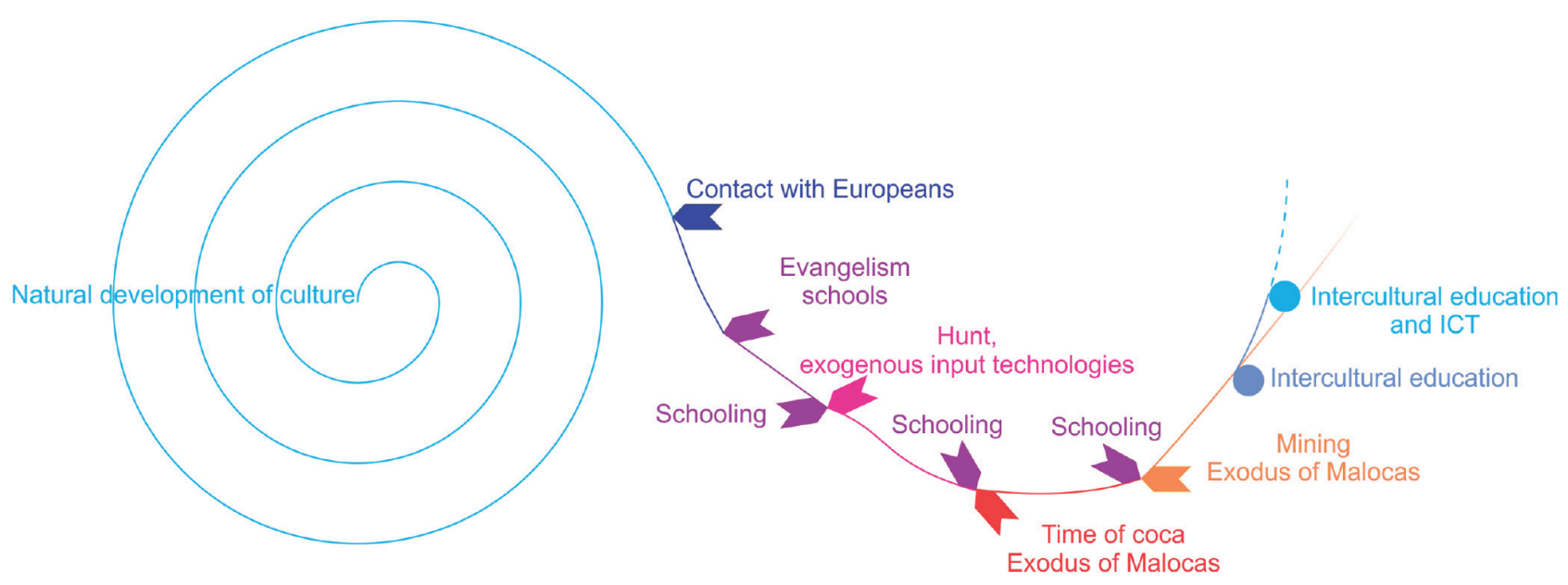

Elaboración de W. Valbuena (marzo de 2013).

Un buen ejemplo de esta situación lo describe Juan Álvaro Echeverri cuando plantea que en otro pueblo de la Amazonía se distingue claramente cómo

La escuela, por muchas vueltas que se le dé y por muchas cosas que se le innoven o suplanten, sigue siendo el espacio de redención para acceder al mundo "blanco", es el vehículo que lo lleva a uno de ser chagrera a ser secretaria. (s. f., p. 1).

Allí ser chagrera (cultivar la tierra como parte de la tradición local) es sinónimo de desprestigio, y, por el contrario, ser secretaria es para una mujer indígena la forma de adquirir reconocimiento social. Similar planteamiento hace Martínez (2012), en términos de la relación entre educación y comunicación liberadora en minorías; apoyándose en el trabajo de Freire, este autor plantea que: "los miembros de minorías suelen albergar una identidad subjetiva negativa que es fruto de su posición social objetiva y que deviene en respuestas emocionales también negativas como una falta de autoestima y un pobre sentido de autoeficacia" (p. 166).
Una educación intercultural debe empezar por reconocer esta historia educativa y plantear formas alternativas para construir un camino diferente en términos de educación, reconociendo que es imposible recomponer el patrón original construido socialmente por las poblaciones indígenas (figura 2), pero, al unísono, sabiendo que el éxito de un modelo educativo legítimo estriba en la participación real de los actuales pobladores de la comunidad.

Todo lo anterior, en relación con la lengua nativa como recurso cultural TIC, base para el desarrollo del modelo educativo, se presenta como un conjunto de elementos de fuerte incidencia en el uso de la lengua indígena; estos momentos son manifestación de alternancias de la TIC tradicional, que, según David Alarcón, al ser realizados por hablantes indígenas y aunque la alternancia no signifique para estos autores necesariamente la pérdida de la lengua, son circunstancias como la educación, el comercio, las relaciones hegemónicas de la sociedad mayoritaria entre muchas otras causas las que afectan el uso de las lenguas indígenas. (2007, p. 30). 
Se entiende que el uso de la lengua es fundamental para el tránsito, la construcción y la innovación de los significados locales entre la comunidad de hablantes: sin estos, mucho de lo cotidiano pierde sentido y la educación pierde su rumbo como artefacto social para el desarrollo de la cultura. Siguiendo a Rossana Reguillo, quien se apoya en el planteamiento de De Certeau sobre la importancia de las redes sociales para asegurar la dinámica y la gestión de estas, se comparte la idea según la cual

la primera condición de la vida cotidiana es esencialmente la comunicación, en la medida en que sus estructuras y lógicas de operación se hacen visibles, no por la repetición o habituación, sino por el sentido subjetivo de la acción que deviene intersubjetivizada en la medida en que el actor social va construyendo, en colectivo, la inteligibilidad de la acción. (Reguillo, 2000, p. 79).

\section{La educación en la actualidad}

En la actualidad, la vida cotidiana en la comunidad no tiene relación con la vida cotidiana en la escuela: la escuela se ha convertido en un simulador poco eficiente de la realidad en la comunidad; los códigos culturales que se alimentan en la escuela aún no se acoplan estructuralmente a los códigos culturales de la comunidad, lo cual manifiesta claramente un problema de comunicación entre el conjunto de intangibles que se usan en la escuela y los que se usan para vivir con la selva.

Como estrategia para empezar a establecer una relación entre los dos mundos del niño, la maloca abre espacios de participación a los profesores y los estudiantes en las actividades tradicionales; sobre todo, las rituales. Estos momentos son considerados momentos de aprendizaje.

Para no perjudicar tanto a los niños, la maloca le abre espacios de participación (...) lo que hacemos es que en ese momento los profes se involucran en las actividades normalmente como cualquier persona, ir a buscar coca, a pilar coca, ir a buscar ceniza, ir a cargar leña, sentarse, bailar, danzar, como cualquiera (...) Algunos profesores no participan, simplemente no quieren, otros se entregan totalmente y los estudiantes les gusta, entonces la estrategia que hemos usado aquí en el Pirá es que, como es un momento de aprendizaje también, [entonces] esos momentos de realización de rituales y danzas, fiestas y todo lo que se hace en una Maloca, ir involucrando en la escuela como contenidos de aprendizaje (sic). (Conversación personal con líder tribal, 2012).

Empero, así como la escuela no involucra de forma contundente la cotidianidad de la vida indígena, en aquellos momentos de aprendizaje del conocimiento tradicional se presenta, así mismo, la anulación del espacio escolar:

la actividad en una maloca sí es propiamente tradicional, porque eso, por ejemplo en un ritual donde se toma yajé, se baila con plumajes sagrados como decimos nosotros por acá [...] los estudiantes, y si participan los profesores, ellos están obligados a quedarse cinco, seis días más, sí porque es un proceso de curación [...] ahí no se puede estar pensando en horas de clase, ni escuela, ni nada en ese momento, después de seis, cinco días sí ya, hasta que el Payé diga: hasta aquí! ya terminó todo esto!, ahí sí ya pueden volver a sus actividades (sic). (Conversación personal con líder tribal, 2012).

No obstante, como estrategia de articulación se desarrollan talleres sobre las experiencias en la maloca o la comunidad. Teniendo esto en cuenta en la actualidad, con Occidente, se puede hablar de multiculturalidad, pero la interculturalidad aún no se materializa en construcciones socioculturales potentes. La educación, que fue en su momento protagonista de la distorsión, ahora debe redefinirse en pro de la innovación social teniendo en cuenta que, como afirma el líder tribal, "la cultura nunca es estable". (Conversación personal con líder tribal, 2012).

Por su parte, las comunidades del Pirá Paraná han desarrollado durante siete años experiencias educativas para materializar la interculturalidad; sin embargo, los maestros que han sido normalistas (formados como docentes en instituciones dirigidas por la Iglesia o el Estado) se resisten a vincular temáticas culturales con actividades escolares, porque: "dicen que eso no es educación; que educación es coger una tiza, 
un tablero, un marcador y empezar a escribir, hemos empezado a hablar mucho con ellos y hay gente que comprende y otra que definitivamente se quedan así". (Conversación personal con líder tribal, 2012)

En el caso de la escuela a la cual asisten actualmente los niños de Caño Toaka, ubicada en la comunidad de Puerto Antonio, la comunidad ha considerado, en primera instancia, que la maloca o cualquier espacio cultural es abierto para la participación de profesores o estudiantes, y, por otra parte, se ha planteado que dentro de su calendario académico se deben contemplar espacios de participación en rituales, como los ya descritos.

Otro punto importante en la educación actual en la comunidad tiene que ver con el perfil de maestro que se está buscando; se comenta que para ser profesor en la zona se requiere ser nativo, conocer la cultura propia, hablar la lengua nativa, tener un buen dominio de expresión del castellano y tener conocimientos académicos básicos. Como se puede evidenciar, los conocimientos sobre uso de TIC exógenas más allá de un uso básico de la lengua castellana, aún no hacen parte de los criterios para definir a un maestro comunitario. De la misma forma, el conocimiento pedagógico acorde con las características socioculturales no es en la actualidad un requisito, pero sí una necesidad, como lo comenta el líder tribal:

Se les ha hecho como diez cursos de capacitación en didáctica y relacionados con muchas pedagogías, pero siempre ha sido muy complicado traer especialistas que conozcan de la didáctica, de la enseñanza, de diferentes tipos de áreas y de pedagogías de acuerdo al pensamiento... al aprendizaje dentro de los colegios. (Conversación personal con líder tribal, 2012).

Aunque los maestros se han formado en didáctica, es muy difícil Ilevar a la zona a expertos en este tema para formar a los docentes; en ese sentido, se manifiesta una necesidad importante: la capacidad didáctica de los maestros comunitarios; ello, sumado a la distancia entre la educación escolarizada y la formación propia en la cotidianidad, hace evidente el problema educativo en relación con la cultura, y por ello se requiere, y con urgencia, una mayor y mejor fundamentación en didáctica intercultural.
Experiencias educativas interculturales actuales en el Pirá Paraná

En el estado del arte que describe Alarcón (2007), se comenta que las experiencias de educación bilingüe en territorios indígenas se caracterizan porque

incluyen en sus planes de estudio tanto contenidos en español, como contenidos en lenguas indígenas. Otros tienen actividades como fiestas tradicionales, encuentros con mayores para narración de historias, elaboración de utensilios, u otras actividades en las que se habla en lengua indígena. (p. 34).

La actualidad educativa en la zona del Pirá Paraná no escapa de esta realidad, a pesar de la latente problemática que plantea la falta de competencias en didáctica intercultural por parte de los maestros comunitarios. Estos han desarrollado por siete años algunas experiencias consideradas exitosas desde el punto de vista de recuperación de la cultura, como en el caso de las comunidades de Santa Isabel o de San Miguel. En la primera, el currículo de la escuela creó una metodología de enseñanza para todas las áreas de formación basada en la labor de la cerámica. Por su parte, en la comunidad indígena de San Miguel el pueblo barazano hace experimentación educativa a partir del plumaje de danza 5 .

Estas experiencias son visibles dentro de las comunidades por medio de los encuentros zonales, considerados estos dispositivos de visibilidad pedagógica (Hernández y Valbuena, 2010) donde se exponen los avances de los procesos educativos locales (foto 1 ). Así mismo, estas experiencias son invisibles para el resto de la sociedad colombiana, para la comunidad científica y para el mundo en general, ya que hacia el exterior su divulgación no supera la entrega de un informe técnico; pero la riqueza cultural, la didáctica y la pedagógica de estas experiencias aún permanecen ocultas en dichos ámbitos.

Estas experiencias, sin duda, han vinculado parte de las culturas indígenas en el trabajo de la escuela, y son un paso firme hacia la construcción de una educación

5 El plumaje de danza es el tocado sagrado de plumas que se usa en los rituales (Banco de la República, 2001) 
intercultural. A pesar de ello, el diálogo de saberes entre las culturas ancestrales y la sociedad mayoritaria no ha sido algo característico de estas experiencias; seguramente, mucho de lo que aún se enseña en la escuela carece de un sentido práctico para los niños, al ser un conocimiento que solo es útil en el mundo de la escuela, pero no en el mundo de la vida. Como ejemplo, se encuentra que el hecho de aprender el castellano no tiene un uso real, pues no existe una comunidad de hablantes de la lengua española en la comunidad, es un conocimiento usado solo por algunos líderes cuando requieren entrar en contacto con personas de la sociedad mayoritaria; pero si estos encuentros no se presentan, el aprendizaje del castellano parece insulso y postizo.

Foto 1. Visibilidad regional.

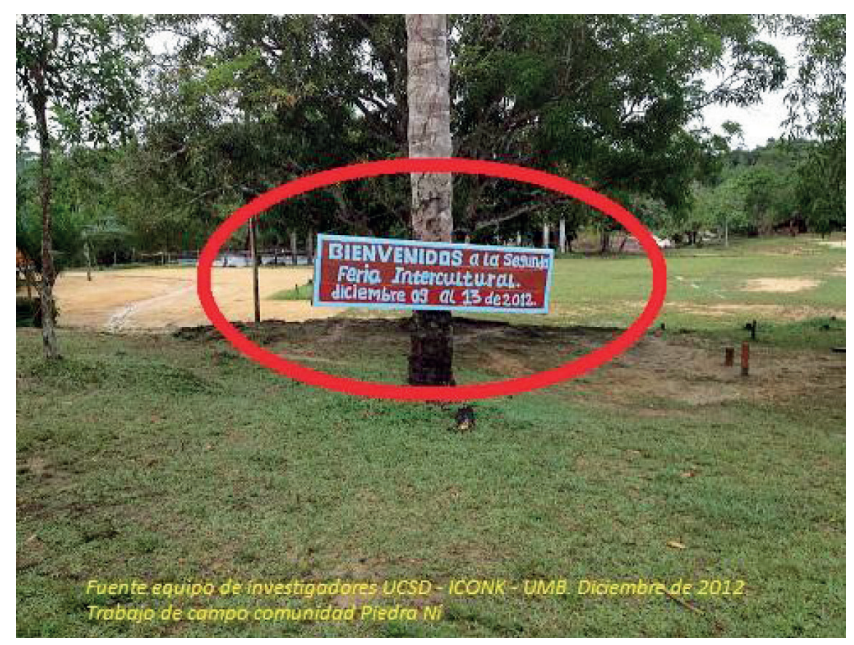

La educación intercultural y las TIC como parte de la respuesta

Teniendo presente el escenario educativo actual en la zona del Pirá Paraná, y, en particular, en la comunidad de Caño Toaka, se considera que las Tıc tienen atributos que, usados de forma culturalmente pertinente, coadyuvan en el fortalecimiento de la cultura makuna.

Uno de esos atributos que poseen las TIC (sobre todo, aquellas digitales) es su potencial para exaltar y visibilizar la cotidianidad, la cual es considerada un componente fundamental en la construcción de una educación intercultural. Igualmente, el uso pedagógico de la visibilidad dentro de un marco de gestión de conocimiento tiene efectos positivos en el aprendizaje (Hernández y Valbuena, 2010).

Otro atributo que se ha encontrado en las TIC es su potencial social para fortalecer el reconocimiento y caminar hacia el empoderamiento (Hernández y Valbuena, 2010). Como cabe recordar, parte de la estrategia utilizada para implementar la evangelización tuvo que ver con la desvalorización y la anulación simbólica de las culturas nativas, lo cual, en consecuencia, derivó en un escaso reconocimiento de estas por parte de los integrantes más jóvenes de la comunidad y, por parte, de un buen número de personas de la sociedad mayoritaria, donde por mucho tiempo el "indio" fue sinónimo de ignorancia, de falta de educación o, incluso, de valores socialmente reprochables. Ahora bien, si las TIC sufren un proceso de apropiación por parte de la comunidad, estas, sin duda, pueden comunicar al resto de la sociedad su riqueza cultural y revertir gradualmente el sentido peyorativo que ha sido atribuido a las sociedades indígenas.

Por otro lado, indudablemente, la interacción ha sido reconocida por lo menos como parte de (1) procesos comunicativos, (2) procesos de aprendizaje y de construcción de conocimiento, (3) componente activo de la visibilidad, (4) agente estructurador de redes sociales, entre otras, y (5) característica intrínseca de las TIC. Esta combinación hace pensar que dichas tecnologías pueden, sin duda, soportar procesos colectivos de construcción heterogénea, donde se fortalezca la identidad social e individual a partir del diálogo y el aprendizaje desde la diferencia.

En ese sentido, la educación debe ser vista como un problema de comunicación, donde se espera que las tecnologías de la información y, sobre todo, de la comunicación aporten de forma contundente.

Otra de las posibilidades que las TIC ofrecen es como instrumento para la protección y el resguardo del conocimiento local y del nuevo conocimiento construido a través de la interacción. En ese sentido, comenta Alarcón (2007), "la conservación del conocimiento ancestral es uno de los aspectos más importantes para todas las culturas indígenas de Colombia lograda por medio de la oralidad y vigente en todas ellas y con el riesgo de convertirse en culturas puramente escritas" (p. 32). 
Junto con lo anterior, se reconoce, igualmente, que las TIC pueden fortalecer la oralidad ampliando el uso común del lenguaje nativo y compartiendo este con otras comunidades de hablantes culturalmente diferentes; esto, teniendo presente que, como considera Alarcón (2007), la oralidad es fundamental en el fortalecimiento cultural, y la palabra es, como ya se ha comentado, la TIC que mayor sofisticación ha tenido en las culturas indígenas en la Amazonía.

La oralidad es tan importante en los procesos educativos de las comunidades que, incluso, es el medio por el cual las personas comunican sus sueños. Como ya se anotó, estos constituyen un imprescindible material cognitivo que, gracias a la atmósfera de la maloca, transitan entre las personas con un propósito muy práctico: contribuir en la educación para la vida. Aquí, las TIC también se muestran como herramientas útiles, no solo asistiendo por medio de la oralidad el tránsito de estos sueños, sino también, gracias a su capacidad, coadyuvando en la construcción de la memoria cotidiana compartiendo los sueños de las personas.

\section{Condición actual de las Tic en la comunidad Caño Toaka y sus alrededores}

Se reconoce que existen diferencias entre las configuraciones del conjunto de culturas que enmarcan el contexto intercultural; sobre todo, cuando se hace un análisis del componente tecnológico para el planteamiento del modelo educativo intercultural para la comunidad de Caño Toaka. Los actores que se reconocen para este modelo intercultural son: la comunidad de Caño Toaka, las comunidades más próximas a la comunidad Caño Toaka, los investigadores de BogotáColombia y los investigadores de Estados Unidos.

Desde los hallazgos del presente estudio exploratorio se encontró que, en particular, en las comunidades indígenas se está haciendo un esfuerzo por incorporar el uso de computadores en sus prácticas cotidianas, con la dificultad de no disponer de manera efectiva de fuentes de energía eléctrica. En la actualidad se utilizan paneles solares, baterías de acumulación y conversores para conectar los computadores. Lo que manifiestan las personas que usan computadores en la comunidad es que "las baterías de acumulación se deterioran muy rápido y esto hace que el uso del computador sea restringido". (Conversación con líder tribal, 2013).

Teniendo en cuenta que la comunidad base para el desarrollo del modelo es la de Caño Toaka, se propone tener un acompañamiento que potencie los procesos de gestión de conocimiento con base en el planteamiento de las organizaciones que aprenden (Nonaka y Konno, 1998). Este planteamiento considera dos elementos que se resaltan en esta investigación: por un lado, la incorporación crítica de tecnologías en los procesos cotidianos de la comunidad; por otro, la gestión de la red social que se viene configurando. Es así como se reconoce que, en términos meramente técnicos, la problemática plantea retos como una eficiente respuesta energética y una infraestructura tecnológica acorde con las condiciones ambientales y culturales del lugar. En este punto, es fundamental superar la tendencia de transferencia tecnológica y apropiación per se, que se ha acostumbrado implementar, sin tener presente la participación real de los miembros de la comunidad, ya que esto desemboca en por lo menos dos tipos de dependencia: técnica y económica, las cuales anulan una legítima autonomía como parte del etnodesarrollo. En términos de Bonfil (1995), solo cuando los sujetos posean la capacidad de decisión sobre recursos culturales exógenos, se puede hablar de un proceso de apropiación que hace del recurso algo propio.

En ese mismo sentido, los escenarios de formación desde el diálogo de saberes para el desarrollo de capacidades en el uso técnico deben estar instalados en todo el proceso de desarrollo tecnológico, de modo que eso contribuya a dicha apropiación transformando un recurso ajeno en uno propio.

Desde el planteamiento de gestión de conocimiento de Nonaka, se identifican algunos retos tecnológicos que atienden al modelo educativo intercultural con incorporación de TIC. En primera instancia, se requiere hacer conciencia de que existe un conocimiento de los actores que no es fácilmente expresado, que cada actor lo ha incorporado con una perspectiva subjetiva; es decir, se encuentra en el interior de los sujetos (conocimiento tácito); por otro lado, la existencia de un conocimiento que es posible expresar con palabras, 
con el diálogo, con bases de datos; es decir, que se encuentra materializado en objetos creados (conocimiento explícito). En un proceso de construcción intercultural, estos elementos constituyen la materia prima intangible para materializar el diálogo de saberes y la acción comunicativa como partes de un método, en procesos realmente participativos, donde no solo se consulta a la comunidad, sino se aprende con ella, y así se pasa de comunidades de práctica a comunidades de innovación.

Un ejemplo específico del manejo de la visibilidad en el contexto del aprendizaje en la comunidad de Santa Isabel se presenta en la estructura de escuela tradicional en un salón de clase, donde se evidencia un dispositivo de visibilidad: este consiste en publicar en una de las paredes los productos académicos de los estudiantes (foto 2) para habilitar la posibilidad de tener reconocimiento del trabajo desarrollado, por los demás miembros de la comunidad (Bandura, 1986).

También desde un análisis del uso pedagógico de la visibilidad, pero con un carácter más amplio, se evidencia el desarrollo de ferias en las que cada comunidad Ileva ciertos productos académicos para mostrarlos, y así configurar una representación de su propia comunidad (foto 2).

\section{Foto 2. Visibilidad interna.}

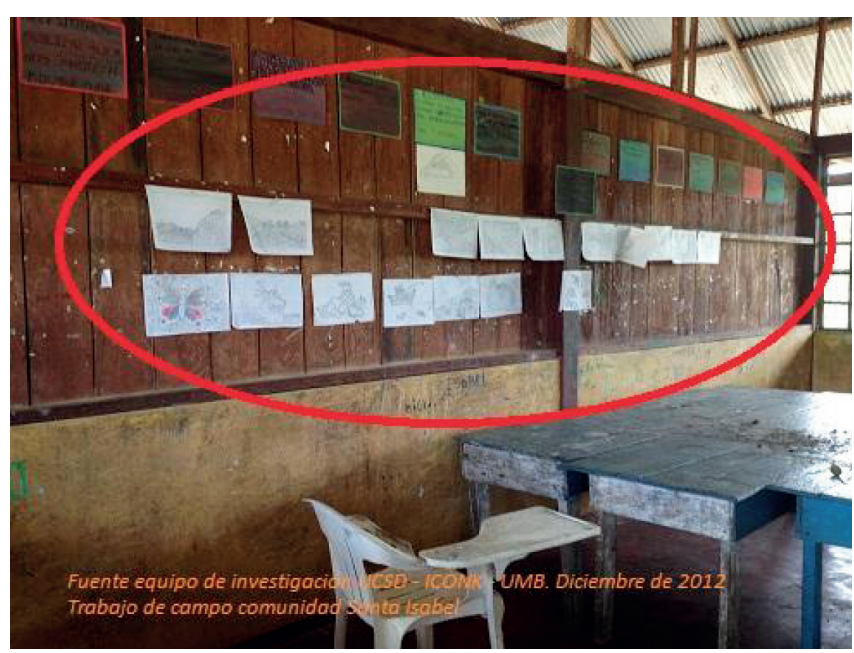

Desde el planteamiento de Hernández y Valbuena (2010), esta dinámica de visibilidad dentro de un proceso de aprendizaje favorece la calidad de los productos si se garantiza la posibilidad de recibir juicios de valor sobre el producto académico y si se cuenta con el tiempo para transformar el producto. En ese sentido, la propuesta de modelo educativo con apoyo de TIC considera que el soporte de las tecnologías se convierte en un recurso muy potente para poder hacer un uso pedagógico de la visibilidad, con lo cual se habilitan otros espacios complementarios de construcción de conocimiento conjunto y un escenario de reconocimiento de lo que hacen los otros que evidencie un diálogo de saberes, y potencie así el componente intercultural.

En el mismo sentido, se entiende que una construcción intercultural pasa por un proceso de hibridación, donde los atributos de uno y otro lado se conjugan para dar origen a un producto culturalmente diferenciado de sus componentes originarios. Igualmente, se entiende que las tecnologías, sin importar su origen, son productos socioculturales, lo cual implica que, en términos de interculturalidad, si un grupo de estas con diferente origen entran en contacto, se genera el potencial para un desarrollo tecnológico híbrido. En el campo de las TIC, se entendería que, si se quiere que estas apoyen procesos interculturales, su desarrollo debe caracterizarse por dicha hibridación y debe emerger del intercambio cultural en un proceso de creación colaborativa (COcreación) vinculando el poder creativo y la diversidad de las personas que participen en los procesos de diseño y desarrollo de estas TIC (Sanders y Stappers, 2008; 2014).

Los productos tecnológicos comunicativos socioculturales híbridos deben, por una parte, recoger la cotidianidad de la comunidad desde las experiencias espaciales y los sueños; por otro, establecer un escenario digital alternativo común, que gradualmente se convierta en cotidiano, de modo que permita la configuración espacial, no en un sustrato material, sino desde un sustrato digital. Es decir, una cotidianidad virtual que se alimenta de la misma construcción simbólica que posee actualmente la comunidad. Y, finalmente, cobra importancia que en estos objetos digitales interculturales converjan los diferentes contextos cotidianos de las personas haciendo que se construyan nuevos espacios cotidianos emergentes, producto de la interacción de las diferentes culturas que hacen parte del diálogo de saberes.

\section{Conclusiones y proyecciones}

Las diferentes formas como las comunidades indígenas se han relacionado con la sociedad mayoritaria se han 
caracterizado por la asimetría, a un grado tan profundo que modela la conducta cotidiana. La apropiación de artefactos occidentales es un ejemplo de esto, donde, claramente, la disputa simbólica entre la eficiencia y la tradición ha sido ganada por la primera.

Se encuentra que la educación que recibe el niño indígena en la cotidianidad y el componente simbólico del fenómeno técnico tienen una relación muy estrecha, donde lo segundo permea todos los aspectos de la vida del niño insertando valores exógenos que se expresan en sus preferencias, sus anhelos y su conducta. Estos valores exógenos, en muchas ocasiones, riñen con los valores propios de la cultura, que, en su mayoría, están en los líderes tribales, y ello ocasiona distanciamientos generacionales o ideológicos entre los miembros de las comunidades indígenas.

El niño indígena actualmente vive en dos entornos educativos diferentes, y, en gran medida, inconexos. Está, por un lado, la educación que recibe a través del ejemplo de sus mayores, donde aprende todo para vivir con la selva6; por otro, está la escuela, que, si bien desde hace siete años ha empezado un proceso de transformación para fortalecer las culturas indígenas, aún tiene vestigios importantes de la conflictiva historia educativa del Pirá Paraná. En la actualidad, ninguno de estos dos tipos de educación proporciona los aprendizajes que le permitan al niño indígena transitar fluidamente entre dos mundos: tanto la educación tradicional indígena como la recibida en la escuela son insuficientes para responder a las actuales demandas interculturales de la comunidad de Caño Toaka.

De igual forma, la educación exige de los maestros comunitarios solidez en una didáctica de la interculturalidad que siga reivindicando la cultura tradicional, pero, al mismo tiempo, les permita educar a sus niños de modo que puedan acceder a otras culturas para fortalecer la propia.

6 Cuando nos referimos al vivir o habitar indígena es importante hablar de "vivir con la selva" y no "vivir en la selva", esto teniendo presente: primero, que para los pueblos indígenas, desde su cosmovisión, las relaciones con lo que en occidente entendemos por naturaleza, no son de subordinación antropocéntrica o de colonización de espacios por parte de los humanos, sino por el contrario, son relaciones de constante co-construcción creativa bidireccional (Cayón, 2013); segundo, desde la perspectiva humanística de los estudios en geografía entendemos que el territorio que genéricamente denominamos como selva es un sistema complejo de espacios significados o lugares (Montoya, 2012), con los cuales es posible el habitar de los pueblos originarios en el soporte biofísico.
El conocimiento ancestral, el conocimiento ecológico, las experiencias de la vida cotidiana con la selva, los sueños proporcionados por la atmósfera de la maloca y la palabra, entre otros, son los recursos culturales propios que se deben tener en cuenta en el momento de alimentar un modelo educativo intercultural.

Por otro lado, el conocimiento técnico occidental, el conocimiento pedagógico y didáctico, la experiencia en investigación y la diversidad disciplinar con diferentes perspectivas son los aportes que desde afuera se pueden articular con el universo de recursos propios de la comunidad de Caño Toaka para construir un modelo educativo intercultural que sea nutrido con TIC.

Si bien las TIC digitales son un recurso cultural exógeno a las comunidades indígenas, se reconoce, igualmente, que estas tienen un conjunto de cualidades que contribuyen al propósito social de construcción de un modelo intercultural bilingüe. Entre estas se cuentan: el potencial para almacenar el acervo cultural de la comunidad; la posibilidad de fortalecer la principal TIC local (es decir, la palabra) generando un espacio alternativo para su uso; la posibilidad de conectar el mundo indígena con el mundo occidental; la posibilidad de fortalecer el reconocimiento de la cultura makuna a través de la visibilidad de las prácticas educativas locales, y el poder amplificador de la voz local hacia el exterior.

El legítimo proceso intercultural debe basarse en la equidad simbólica, el reconocimiento mutuo, el aprendizaje conjunto, la construcción colaborativa de conocimiento y la constante reflexión crítica del uso y el desarrollo colaborativo de TIC.

El repositorio digital se entiende como un artefacto de visibilidad que cumple con las necesidades de la comunidad en términos de hacer gestión de la información disponible. Este proceso de gestión puede entenderse de dos maneras: (1) la visibilidad interna, en términos que los actores de la comunidad puedan reconocer sus propias producciones y tener un escenario de interacción que permita procesos de construcción conjunta; (2) la visibilidad externa de la comunidad en términos de lo que se quiere mostrar hacia el exterior. Especialmente, este segundo punto se refiere a la necesidad expresada por la comunidad en términos de su reconocimiento en el mundo exterior. Esta idea de repositorio, finalmente, es entendida como un recurso 
tecnológico que apoya el planteamiento de gestión de conocimiento en el que se apoya la idea del modelo de educación intercultural bilingüe.

Desde la definición de ODEI, se reconoce la pertinencia del soporte de las TIC desde una mirada del desarrollo de la visibilidad interna y externa en las comunidades del Pirá Paraná, con la pretensión de potenciar los procesos de construcción de conocimiento y la activación del reconocimiento de los actores y las comunidades.

Es importante que el desarrollo de los ODEl garantice la acción comunicativa (Habermas y Redondo, 2001), con el fin de habilitar el diálogo de saberes entre culturas, y que dé como resultado la configuración de nuevos significados interculturales. Para garantizar esto, se debe dar por superada la divisoria digital (Castells, 2000); es decir, garantizar que todas las culturas que configuran el ambiente intercultural ingresen en un proceso de apropiación de los distintos recursos culturales disponibles, a través de la materialización del poder de decisión sobre estos recursos (Bonfil, 1995).

Los hallazgos del presente estudio exploratorio proporcionan los elementos para construir un modelo de ejecución que permita avanzar en el desarrollo tecnológico y pedagógico de lo que se ha denominado ODEI. En ese sentido, se ha planteado como parte de las proyecciones el modelo de ejecución (figura 3), el cual está basado en la propuesta metodológica de design thinking (Brown, 2008). Aunque este modelo es vigente, en la actualidad se ha planteado un modelo de diseño y desarrollo desde la co-creación y el co-diseño, más pertinente con el propósito que se persigue (Sanders y Stappers, 2008; 2014).

Según este modelo, los componentes 1, 2 y 3 son los que han permitido establecer los resultados expuestos en el presente documento (figura 3). En ese sentido, las etapas de prototipado, implementación, iteración y de nuevamente comprensión hacen parte de las proyecciones. Es así que el equipo de investigación se adentra en el desarrollo de por lo menos tres componentes del modelo educativo intercultural: (1) el que se ubica en el desarrollo tecnológico de la infraestructura de comunicación, a partir del trabajo de redes comunitarias; (2) el desarrollo de los primeros prototipos de los ODEI basados en conocimiento ancestral, conocimiento ecológico local y la vida cotidiana con la selva amazónica, y (3) el planteamiento de un modelo de gestión de conocimiento intercultural.

Los mencionados componentes ingresan en proceso de implementación con la participación total de la comunidad de Caño Toaka, la cual, con su valiosa colaboración, permitirá, en un proceso iterativo, refinar los prototipos haciéndolos de verdad pertinentes. Lo anterior, dando entrada a un nuevo proceso de investigación, para luego comprender los impactos y delimitar nuevos problemas de investigación.

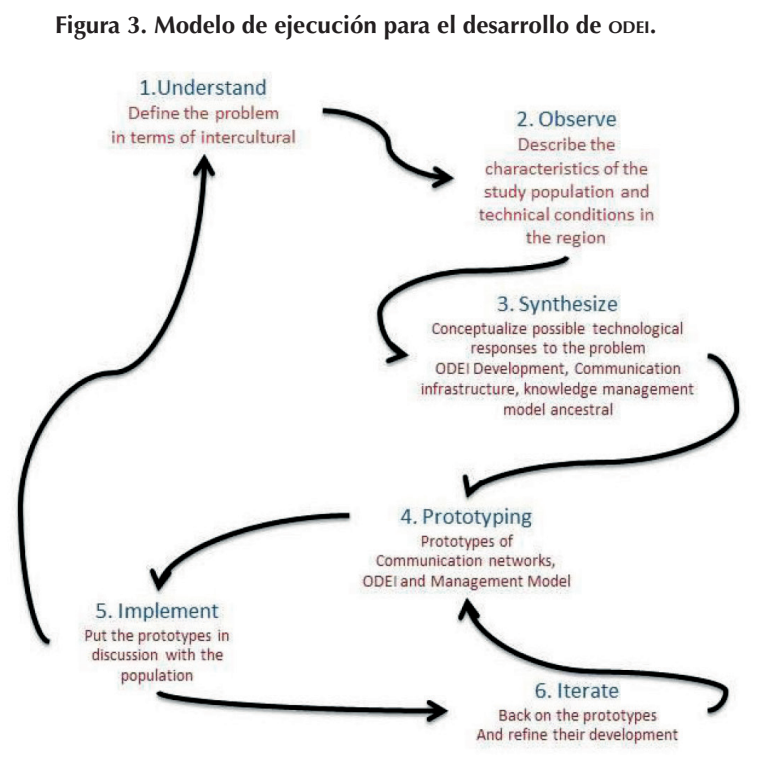

Adecuación de Montoya y Valbuena (2013). 


\section{Referencias}

Alarcón, D. (2007). Bilingüismo indígena en Colombia. Revista Colombiana de educación bilingüe, 1, 24-38.

Århem, K. (2004). Etnografía Makuna: tradiciones, relatos y saberes de la Gente de Agua. Acta universitatis Gothoburgensis. Recuperado de: http://books.google.com.co/books?id=EcASAQAAIAAJ

Århem, K., Cayón, L., Angulo, G. y García, M. (2004). Etnografía Makuna: tradiciones, relatos y saberes de la Gente de Agua (p. 575). Recuperado de: http://swepub.kb.se/bib/ swepub:oai:services.scigloo.org:40358

Baker, C. (2001). Foundations of Bilingual Education and Bilingualism. Multilingual Matters. Recuperado de: http://books.google. es/books?id=fEt5VKBIMSsC

Banco de la República. (2001). Makuna. La gente del agua. Catálogo Banco de La República. Bogotá. Recuperado de http://www. banrepcultural.org/sites/default/files/makuna.pdf

Bandura, A. (1986). Social foundations of thought and action: a social cognitive theory (p. 617). Prentice-Hall. Recuperado de: http:// books.google.com.co/books?id=HJhqAAAAMAAJ

Bonfil, G. (1995). El Etnodesarrollo: sus premisas jurídicas, políticas y de organización. America latina (2), 464-480. Recuperado de: http://mail.udgvirtual.udg.mx/biblioteca/ bitstream/20050101/1269/2/El_etnodesarrollo.pdf

Bauman, Z. (2000). Modernidad líquida. México: Fondo de Cultura Económica.

Bauman, Z. (2007). Vida de consumo. Buenos Aires: Fondo deCultura Económica. Recuperado de: http://scholar.google.com/ scholar?hl=en\&btnG=Search\&q=intitle:Vida+de+consumo\#4

Boast, R., Bravo, M. y Srinivasan, R. (2007). Return to Babel: Emergent diversity, digital resources, and local knowledge. The Information Society (december), 1-31. Recuperado de: http:// www.tandfonline.com/doi/abs/10.1080/01972240701575635

Brighenti, A. (2010). Visibility in Social Theory and social research. Recuperado de: http://www.capacitedaffect.net/2013/teoriasociale2014/Brighenti_2010_Urban_Visibilities.pdf

Brown, T. (2008). Design thinking. Harvard business review, 86 (6), 84-92, 141. Recuperado de: http://www.ncbi.nlm.nih.gov/ pubmed/18605031

Castells, M. (2000). Internet y la sociedad en red. Conferencia de Presentación del Programa de Doctorado sobre la Sociedad de la Información y el Conocimiento. Universitat Oberta de Catalunya, pp. 1-19.

Cayón, L. (2008). Ide Ma: El camino del agua. Espacio, Chamanismo y persona entre los Makuna. Antipoda (7), 141-173.

Cayón, L. (2013). Pienso, luego creo: la teoría makuna del mundo. Bogotá: Instituto Colombiano de Antropología e Historia.

Descola, P. y Palsson, G. (2013). Nature and Society: Anthropological Perspectives. Recuperado de: http://books.google.com.co/ books?id=5FxatUoNIRUC

Echeverri, J. (s. f.). ¿De Chagrera a Secretaria? Balance de algunas acciones en etnoeducación en el Amazonas colombiano. humanas.unal.edu.co. Recuperado de: http://www.humanas.
unal.edu.co/colantropos/documentos/EcheverriChagreraSecretaria.pdf

Estébanez, A. (1982). La Geografía Humanística. Anales de Geografía de la Universidad Complutense, 2. Recuperado de: http://revistas.ucm.es/index.php/AGUC/article/view/ AGUC8282110011A/32153

Ferrão, M. (2010). Educación Intercultural en America Latina: Distintas concepciones y tensiones actuales. Estudios Pedagógicos, 34 (2), 333-342.

García, N. (2004). Representaciones e interculturalidad. Diferentes, desiguales o desconectados. Revista CIDOB d'Afers Internacionals, 66 (67), 113-133.

Guber, R. (2001). La etnografía. Método, campo y reflexividad. Bogotá: Grupo Editorial Norma.

Gutiérrez, K. (2008). Developing a Sociocritical Literacy in the Third Space. Reading Research Quarterly, 43 (2), 148-164. doi:10.1598/RRQ.43.2.3.

Habermas, J. y Redondo, M. (2001). Teoría de la acción comunicativa: complementos y estudios previos. Cátedra. Recuperado de: http://books.google.com.co/books?id=5mjSiji8OxEC

Heath, S. (1993). La Política del lenguaje en México: de la colonia a la nación. Instituto Nacional Indigenista. Recuperado de: http:// books.google.es/books?id=MD6SAAAACAAJ

Hernández, J. y Valbuena, W. (2010). Visibilidad de los actores en una comunidad de aprendizaje, una mirada desde el análisis de redes sociales. Revista de investigaciones UNAD, Suplemento memorias $V$ Encuentro nacional de investigación, 9, 15-26.

Hornberger, N. (1998). Language policy, language education, language rights: Indigenous, immigrant, and international perspectives. Language in Society, 27 (04), 439-458. doi:10.1017/ S0047404598004011

López, L. y Sichra, I. (2008). Intercultural bilingual education among indigenous peoples in Latin America. Encyclopedia of language and education, 1-15. Recuperado de: http://link.springer.com/ openurl?id=doi:10.1007/978-0-387-30424-3_132\&from=SL

Lugo, M. y Kelly, V. (2010). Tecnología en educación ¿Políticas para la innovación? Recuperado de: http://sedici.unlp.edu.ar/ handle/10915/18441

Martín-Barbero, J. (2008). Diversidad cultural y convergencia digital. Revista Científica de Información y Comunicación, 5, 12-25. Recuperado de: http://institucional.us.es/revistas/ comunicacion/5/01barbero.pdf

McCarty, T. (2003). Revitalising Indigenous Languages in Homogenising Times. Comparative Education, 39 (2), 147-163. doi:10.1080/03050060302556

Montoya, A. (2012). Desrepres-arte con trazos y manchas. Habitar la escuela por medio de la imagen gráfica(tesis de maestria). Universidad Pedagógica Nacional, Bogotá.

Morin, E. (1999). La cabeza bien puesta: repensar la reforma, reformar el pensamiento. Nueva Visión

Morin, E. (2004). La epistemología de la complejidad. Gaceta de Antropología, 20 (02), 1-14. Recuperado de: http://www.ugr. es/ pwlac/G20_02Edgar_Morin.pdf 
Moya, R. (1999). La educación intercultural bilingüe: ¿Respuesta frente a la multietnicidad, pluriculturalidad y multilingüismo latinoamericanos? In M. Yamada y C.I. Degregori (Eds.) Estados nacionales, etnicidad y democracia en América Latina (n. ${ }^{\circ}$ 15, pp. 7-30.). Osaka: Japan Center for Area Studies, National Museum of Ethnology.

Nonaka, I. y Konno, N. (1998). Creation, The concept of "Ba": Building a Foundation for Knowledge. California Management Review, 40 (3), 40-54. Recuperado de: http://km.camt.cmu. ac.th/mskm/952701/Extra materials/Nonaka 1998.pdf

Ortiz, R. y Aguilar, T. (2010). Lengua, Cultura y TIC. Un trinomio perfecto, pp. 479-493. Recuperado de: http://fel.uqroo.mx/ adminfile/files/memorias/ortiz_carraco_maria_concepcion_ aguilar_gomez_tania_elena.pdf

Osorio, C. (2002). Enfoques sobre la tecnología. Revista Iberoamerica de Ciencia, Tecnología, Sociedad e Innovación, 2. Recuperado de: http://www.oei.es/historico/revistactsi/numero2/osorio.htm

Rappaport, J. (2005). Intercultural Utopias: Public Intellectuals, Cultural Experimentation, and Ethnic Pluralism in Colombia. Recuperado de: http://books.google.com/books?hl=es\&lr=\&id=NIVB05CVj_ kC\&pgis $=1$

Reguillo, R. (2000). La clandestina centralidad de la vida cotidiana. En A. Lindón (Coord.). La vida cotidiana y su espacio-temporalidad (pp. 77-94). Barcelona: Anthropos-CRIM-El Colegio Mexiquense.

Sanders, E. B.-N., y Stappers, P. J. (2008). Co-creation and the New Landscapes of Design. CoDesign, 4 (1), 5-18. http://doi. org/10.1080/15710880701875068
Sanders, E. B.-N., y Stappers, P. J. (2014). Convivial Toolbox: Generative Research for the Front end of Design.

Schmelkes, S. (2004). La educación intercultural: un campo en proceso de consolidación. Revista Mexicana de Investigación Educativa, 9, 9-13.

Scribano, A. (2004). Conocimiento socialmente disponible y construcción de conocimiento sociológico desde América Latina. Revista Investigaciones Sociales, VIII (12), 289-311. Recuperado de: http://sisbib.unmsm.edu.pe/bibvirtualdata/publicaciones/ inv_sociales/N12_2004/a13.pdf

Sosa, M., Peligros, S. y Díaz, D. (2010). Buenas prácticas organizativas para la integración de las TIC en el sistema educativo extremeño. TESI, 11 (1), 5-445. Recuperado de: http://gredos. usal.es/jspui/handle/10366/72867

Tubino, F. (2005). La interculturalidad crítica como proyecto éticopolítico. Secretaría-General de la O.A.L.A. Recuperado el 1 de agosto de 2013, de: from http://oala.villanova.edu/congresos/ educacion/lima-ponen-02.html

Valbuena, W. (2006). Wi Ketioka, la casa del conocimiento. Lectura compleja del hábitat Makuna (Wi). Una expresión hologramática, un habitar dialógico del pueblo indígena Ide masã "la gente del agua" (tesis de maestria). Universidad Nacional de Colombia, Bogotá.

Vygotsky, L. (1978). Interaction between learning and development. Readings on the development of children (pp. 79-91). Recuperado de: http://scholar.google.com/scholar?hl=en\&btnG=Search $\& q=$ intitle:Interaction+between+learning+and+development $\# 0$ 


\section{Diálogo del conocimento}

El artículo presenta una reflexión en relación con el lugar de las Tecnologías de la Información y la Comunicación en el desarrollo de modelos educativos interculturales. Los autores consideran que la inserción de las TIC en las comunidades indígenas puede constituirse en una entrada más del mundo occidental, imponiendo a través de la violencia simbólica estereotipos y concepciones de mundo que socaban las culturas locales, sin embargo, consideran que mediante modelos participativos y un permanente diálogo de saberes, las Tic pueden constituirse como un fenómeno comunicacional para las comunidades amazónicas que fortalece la cultura local.

El escrito realiza un análisis interesante acerca del rol de la escuela y del maestro en los procesos de apropiación de artefactos tecnológicos por parte de las comunidades indígenas. Usualmente, la introducción de estos se hace a través de la escuela y, en la mayoría de los casos, genera desplazamiento de conocimientos locales, dándose así una dicotomía entre el saber de la escuela y el saber cotidiano de las comunidades indígenas. El artículo, en el fondo, hace un llamado de atención a los maestros para que reconozcan e incorporen los saberes locales en la escuela y así, hacer posible la implementación de un modelo educativo intercultural. El caso de las comunidades del Pirá Paraná -donde los líderes indígenas han tratado de involucrar a los maestros y estudiantes en las actividades de la Maloca, y la respuesta de los educadores ha sido de no participar en razón a que esto no lo consideran educación- lleva inevitablemente a cuestionarnos por la formación que se está impartiendo en las escuelas normales y universidades.

La construcción de un modelo educativo intercultural no puede dejar de lado las TIC, ya que estas, al ser un fenómeno comunicativo, tienen la propiedad de visibilizar, reconocer y gestionar conocimientos locales que pueden entrar en diálogo con otros a través de la constitución de redes, generando así efectos positivos en los aprendizajes y potenciando el empoderamiento de las comunidades indígenas. Sin embargo, estos atributos no son intrínsecos de la tecnología, es necesario que sean direccionados en tal sentido, es allí donde los docentes y líderes comunales tienen un rol fundamental para establecer puntos de encuentro y de distanciamiento entre los saberes locales y el saber occidental.

Finalmente, es necesario reconocer la importancia de este tipo de investigaciones. Por una parte, aportan evidencias empíricas que ayudan a comprender las tensiones inherentes a la educación intercultural y por otra, ponen de manifiesto los retos que tienen los docentes y las instituciones formadoras de maestros frente a la preservación y fortalecimiento del conocimiento ancestral y ecológico de las comunidades indígenas del país.

Camilo Andrés Valderrama Alarcón 